\title{
From Las Vegas to Jacksonville
}

\author{
Brad Hokanson ${ }^{1}$
}

Published online: 28 September 2016

(C) Association for Educational Communications \& Technology 2016

Each year we gather at the annual AECT International Convention and connect with our colleagues, learn of their work, and become inspired by new ideas. This year's convention in October was no different, with diverse keynotes from Cirque du Soleil, Philip Yenawine, and Barry Kudrowitz. They were unique presentations, paired with the entertaining venue of Las Vegas.

Learning From Las Vegas was the theme for the conference, a learning that came from meeting others, hearing their ideas and their stories, and from presenting our own work. That learning will stay with us, as it is applied and built upon in our own professional lives.

There were so many different opportunities at the convention ranging from presenting to a few colleagues to the general sessions; from the hubbub of the university reception to the intense focus of the Breakfast of Champions or the personalized explanation of ideas in the roundtables. And, of course, encountering an unexpected friend in the hallway or a gem of an idea that was never expected.

Why we attend conferences in person recognizes the value of personal interaction and social connection. While we often get information and material from a distance and we meet with colleagues online and on the phone, the direct, personal engagement with our peers, friends, and other professionals is most valuable. As we reminisce about our great experiences in Las Vegas, we can also look forward to our next gathering in Jacksonville in November.

So as the newest president of AECT, I invite you to make your plans and your own proposals to present at our forthcoming gathering in Jacksonville. Elsewhere are the details and the full call for proposals. You should consider this a personal invitation to share your ideas and your work as well as your involvement in a truly great organization.

Brad Hokanson, University of Minnesota College of Design, 2017 President of AECT
Brad Hokanson

brad@aect.org

1 University of Minnesota College of Design, St. Paul, Minnesota, USA 